Arens, A. Katrin; Hasselhorn, Marcus

\title{
Differentiation of competence and affect self-perceptions in elementary school students. Extending empirical evidence
}

formal und inhaltlich überarbeitete Version der Originalveröffentlichung in:

formally and content revised edition of the original source in:

European journal of psychology of education 30 (2015) 4, S. 405-419

\author{
Bitte verwenden Sie in der Quellenangabe folgende URN oder DOI / \\ Please use the following URN or DOI for reference: \\ urn:nbn:de:0111-pedocs-179967 \\ 10.25656/01:17996
}

https://nbn-resolving.org/urn:nbn:de:0111-pedocs-179967

https://doi.org/10.25656/01:17996

\section{Nutzungsbedingungen}

Gewährt wird ein nicht exklusives, nicht übertragbares, persönliches und beschränktes Recht auf Nutzung dieses Dokuments. Dieses Dokument ist ausschließlich für den persönlichen, nicht-kommerziellen Gebrauch bestimmt. Die Nutzung stellt keine Übertragung des Eigentumsrechts an diesem Dokument dar und gilt vorbehaltlich der folgenden Einschränkungen: Auf sämtlichen Kopien dieses Dokuments müssen alle Urheberrechtshinweise und sonstigen Hinweise auf gesetzlichen Schutz beibehalten werden. Sie dürfen dieses Dokument nicht in irgendeiner Weise abändern, noch dürfen Sie dieses Dokument für öffentliche oder kommerzielle Zwecke vervielfältigen, öffentlich ausstellen, aufführen, vertreiben oder anderweitig nutzen.

Mit der Verwendung dieses Dokuments erkennen Sie die Nutzungsbedingungen an.

\section{Terms of use}

We grant a non-exclusive, non-transferable, individual and limited right to using this document.

This document is solely intended for your personal, non-commercial use. Use of this document does not include any transfer of property rights and it is conditional to the following limitations: All of the copies of this documents must retain all copyright information and other information regarding legal protection. You are not allowed to alter this document in any way, to copy it for public or commercial purposes, to exhibit the document in public, to perform, distribute or otherwise use the document in public.

By using this particular document, you accept the above-stated conditions of use.

\section{Kontakt / Contact:}

peDOCS

DIPF | Leibniz-Institut für Bildungsforschung und Bildungsinformation Informationszentrum (IZ) Bildung

E-Mail: pedocs@dipf.de

Internet: www.pedocs.de 
This is a post-peer-review, pre-copyedit version of an article published in European Journal of Psychology of Education. The final authenticated version is available online at: http://dx.doi.org/10.1007/s10212-015-0247$\underline{8}$ 
Running Head: Competence and Affect Self-Perceptions

Differentiation of Competence and Affect Self-perceptions in Elementary School Students:

Extending Empirical Evidence

A. Katrin Arens \& Marcus Hasselhorn

(Center for Research on Individual Development and Adaptive Education of Children at Risk (IDeA), German Institute for International Educational Research, Germany)

Authors' Note:

The authors would like to thank Alexandre J. S. Morin, Ulrich Trautwein, and Benjamin Nagengast for their helpful comments on earlier drafts of this manuscript. Data collection was funded by Hector Foundation II and carried out by the scientific advisory group of the Hector Children's Academy in Baden-Württemberg (Germany) headed by Ulrich Trautwein and Marcus Hasselhorn

Corresponding Author:

A. Katrin Arens, Center for Research on Individual Development and Adaptive Education of Children at Risk (IDeA), German Institute for International Educational Research, Schloßstraße 29, D-60486 Frankfurt am Main, Germany, Telephone: + 496924708 138, Email: arens@dipf.de

This is the prepublication version of the following manuscript:

Arens, A.K., \& Hasselhorn, M. (2015). Differentiation of competence and affect selfperceptions in elementary school students: Extending empirical evidence. European Journal of Psychology of Education, 30, 405-419. http://doi.org/10.1007/s10212-015-0247-8

This paper is not the copy of record and may not exactly replicate the authoritative document published in European Journal of Psychology of Education. 


\begin{abstract}
This study aimed to address two underexplored research questions regarding support for the separation between competence and affect self-perceptions due to differential relations to outcome criteria. First, it is tested whether higher relations between affect self-perceptions and effort than between competence self-perceptions and effort can also be found for elementary school students. Second, this study examines the generalizability of such differential outcome relations to the verbal domain. Students' competence and affect selfperceptions in math and verbal domains and self-reported effort at school were measured in a sample of 156 German $3^{\text {rd }}$ grade elementary school students. Confirmatory factor analyses demonstrated separate factors for competence and affect self-perceptions in both math and verbal domains. Latent regression analyses showed that affect self-perceptions were more highly related to effort than competence self-perceptions. With these findings, the present study adds further support to the commonly accepted separation between competence and affect self-perceptions by demonstrating their differential relations to effort and extending this finding to elementary school students and the verbal domain.
\end{abstract}

Key words: competence self-perceptions; affect self-perceptions; academic effort; differentiation 


\section{Competence-Affect Separation in Motivation Research}

In educational research, students' competence and affect self-perceptions have been conceptualized as separate yet interacting and related components of student motivation predicting a wide range of educational outcomes including achievement, effort, choice, or aspirations (Schunk, Pintrich, \& Meece, 2009). Competence self-perceptions have been conceptualized as students' self-evaluation of ability (also labeled self-concept, Marsh, 2007; also see Nagengast et al., 2011; Trautwein et al., 2012), as outcome expectations (Wigfield \& Eccles, 2000), or as self-efficacy (Bandura, 1977). Affect self-perceptions present a broad term spanning a wide range of constructs pertaining to students' subjective, hence, selfdescribed motivational-affective responses. In the expectancy-value model proposed by Eccles and colleagues (e.g., Eccles \& Wigfield, 1995; Nagengast et al., 2011), one of the best known models differentiating between competence and affect self-perceptions, affect-self perceptions fall into the category of the value component which itself was stated to comprise four different facets: intrinsic value (enjoyment, interest), attainment value (subjective importance), utility value (subjective usefulness), and cost (negative consequences of choosing and engaging in a task, and opportunity cost) (Wigfield \& Eccles, 2000). Although these four value facets have been assumed to be theoretically separable, they were found to be highly interrelated (e.g., Eccles, Wigfield, Harold, \& Blumenfeld, 1993). Therefore, some previous studies applied combined subscales (e.g., a combined scale for usefulness and importance in the study of Wigfield and Eccles, 1994 and in the study of Wigfield et al., 1997), or even a general indicator of positive affect (e.g., a general task value scale integrating students' interest, fun, perceived importance, and perceived usefulness in the study of Jacobs, Lanza, Osgood, Eccles, and Wigfield, 2002). Other studies, in turn, only focused on single constructs such as enjoyment (Pinxten, Marsh, De Fraine, Van Den Noortgate, \& Van 
Damme, 2014), interest (Krapp, 1999), or importance ratings (Eccles et al., 1989). Therefore, there is variety in the operationalization of competence and affect self-perceptions contingent upon the theoretical background and empirical foundations of studies. Notwithstanding their operationalization, competence and affect self-perceptions have coherently been found to constitute separate constructs. Respective evidence originates from within-network studies using confirmatory (CFA) and exploratory factor analyses (EFA) to examine the internal structure of self-perceptions, as well as from the between-network approach testing for differential outcome relations (see Byrne, 1984 for the distinction between within-network and between-network approaches). In essence, competence self-perceptions and affect selfperceptions emerged as separate factors in EFA and CFA (Abu-Hilal, Abdelfattah, Alshumrani, Abduljabbar, \& Marsh, 2013; Arens, Yeung, Craven, \& Hasselhorn, 2011; Marsh \& Ayotte, 2003; Marsh, Craven, \& Debus, 1999; Wigfield \& Eccles, 2000). These kinds of analysis have further illustrated the domain specificity of competence and affect selfperceptions. Hence, students hold specific competence and affect self-perceptions for math and verbal domains instead of global, domain-unspecific academic self-perceptions (e.g., Brunner et al., 2010; Bong, 2001; Eccles et al., 1993; Goetz, Frenzel, Hall, \& Pekrun, 2008; Marsh, 1990c; Marsh \& Yeung, 1996; Möller, Pohlmann, Köller, \& Marsh, 2009; Wigfield et al., 1997). From the between-network perspective (Byrne, 1984), the domain specificity of academic self-concept as well as the distinctiveness between competence and affect selfperceptions have been supported by findings of differential outcome relations. Supporting the domain specificity, higher relations were found between self-perceptions and outcome variables (e.g., achievement, coursework selection) of matching domains (i.e., higher relations between math self-perceptions and math achievement; Marsh \& Craven, 1997, 2006; Valentine, DuBois, \& Cooper, 2004). Supporting the separation between competence and affect self-perceptions, research has demonstrated higher relations between competence selfperceptions and academic achievement than between affect self-perceptions and academic 
achievement (Arens et al., 2011; Meece, Wigfield, \& Eccles, 1990; Pinxten et al., 2014; Wigfield, 1994). Affect self-perceptions, in turn, were found to share higher relations to academic behavior including effort expenditure (Pinxten et al., 2014) and course enrollment choices (Marsh et al., 2013; Meece et al., 1990; Nagy, Trautwein, Baumert, Köller, \& Garrett, 2006).

Many studies focusing the differentiation between competence and affect selfperceptions have been conducted with secondary school children, but fewer studies have addressed this issue with younger children in elementary school. While there is still some within-network evidence that elementary school students differentiate between competence and affect self-perceptions (Arens et al., 2011; Marsh \& Ayotte, 2003; Wigfield \& Eccles, 2000), the situation becomes more unsatisfactory for between-network evidence.

Corresponding to the findings with older students, Arens et al. (2011) and Pinxten et al. (2014) demonstrated that competence self-perceptions were more highly related to achievement compared to affect self-perceptions in both math and verbal domains for $3^{\text {rd }}$ and $4^{\text {th }}$ grade elementary school students. Even fewer between-network studies with young children, however, have adopted the perspective of affect self-perceptions and thus have verified higher relations between affect self-perceptions and behavioral outcomes than between competence self-perceptions and behavioral outcomes. In the study of Pinxten et al. (2014), students' effort expenditure was only assessed from grade level 4 onwards.

Consequently, support for the separation between competence and affect self-perceptions due to the relatively higher relation between affect self-perceptions and effort expenditure was only provided for children in late elementary school years. Studies taking course enrollment choices as a behavioral outcome also demonstrated relatively higher relations for affect selfperceptions compared to competence self-perceptions, but these studies have so far been conducted with samples of secondary school students (Marsh et al., 2013; Meece et al., 1990; Nagy et al., 2006). For elementary school students below grade level 4, to date, no study has 
rendered empirical evidence that affect self-perceptions are more highly related to behavioral outcomes than competence self-perceptions.

Another shortcoming is that findings demonstrating higher relations between affect self-perceptions and behavioral outcomes relative to competence self-perceptions have so far been restricted to the math and science domains. Pinxten et al. (2014) demonstrated that math enjoyment was more highly related to effort expenditure in math than self-perceptions of math competence. Meece et al. (1990) demonstrated a relatively higher predictive value for math value beliefs on students' intentions to enroll in math courses. In the study by Marsh et al. (2013), the measures for students' competence and affect self-perceptions and outcome variables (achievement, plans to take more coursework, and educational aspiration) refer to the domains of math and science. Similarly, Nagy et al. (2006) applied measures for students' competence and affect self-perceptions and course choice in math and biology. However, given the domain specificity of cognitive and affective self-perceptions (e.g., Bong, 2001; Eccles et al., 1993; Marsh, 1990c; Marsh \& Yeung, 1996, Möller et al., 2009), the finding that affect self-perceptions display relatively higher relations to behavioral outcomes than competence self-perceptions cannot automatically be generalized to the verbal domain. For example, previous research consistently demonstrated that both math and verbal competence self-concepts are substantially related to achievement in the corresponding domain (Marsh \& Craven, 1997, 2006). Yet, the relations tend to be stronger and more clear-cut for the math domain (Marsh \& Yeung, 1998). Therefore, relations between affect self-perceptions and outcome variables might also vary across math and verbal domains.

\section{The Present Study}

The present study aims to approach two yet underexplored issues regarding evidence for the separation between competence and affect self-perceptions resulting from their differential relations to effort as a behavioral outcome, namely the generalizability to younger elementary school students and to the verbal domain. For this purpose, we measured 
competence self-perceptions and affect self-perceptions in both math and verbal domains along with school effort in a sample of $3^{\text {rd }}$ grade elementary school children.

To operationalize students' competence and affect self-perceptions, we draw on the Self-Description Questionnaire (SDQ) I (Marsh, 1990a), an instrument which seems particularly suitable to the aim of our study. The SDQ I is part of the psychometrically sound and widely used series of SDQ instruments to assess students' multiple self-concepts (i.e., self-perceptions) in different age groups [SDQ I for preadolescents (Marsh, 1990a), SDQ II for adolescents (Marsh, 1990b), and SDQ III for older adolescents and young adults (Marsh \& O’Neill, 1984); for an overview see Byrne, 1996; Leach, Henson, Odom, \& Cagle, 2006; Marsh, 2007]. These instruments consist of separate domain-specific academic self-concept scales (i.e., math, verbal, general school) and thus consider the commonly accepted domain specificity of self-perceptions, a finding that was even largely substantiated by research on the SDQ instruments (e.g., Marsh, 1990c; Möller et al., 2009; Möller, Retelsdorf, Köller, \& Marsh, 2011). The various academic self-concept scales encompass competence-related items asking for students' self-perceptions of competence. These items have been previously used to operationalize competence self-perceptions to test presumptions regarding the expectancyvalue theory and therefore have already been applied to study research questions beyond selfconcept research and theory (Trautwein et al., 2012). Next to competence-related items, the academic self-concept scales of the SDQ instruments also encompass affect-related items referring to students' liking and enjoyment. Research on the SDQ I supported the distinction between competence and affect self-perceptions, as the competence-related and affect-related items constituting the SDQ I verbal, math, and general school self-concept scales were found to form separate factors in CFA studies (Abu-Hilal et al., 2013; Arens et al., 2011; Marsh \& Ayotte, 2003; Marsh et al., 1999). Besides this within-network evidence, also by using the respective SDQ I items, Arens et al. (2011) demonstrated that competence self-perceptions were more highly related to academic achievement than affect self-perceptions. Research 
findings furthermore indicate the cross-cultural validity of the distinction between competence and affect self-perceptions assessed by SDQ scales (German: Arens et al., 2011; French-Canadian: Marsh \& Ayotte, 2003; Australian: Marsh et al., 1999; Indigenous Australian: Arens, Bodkin-Andrews, Craven, \& Yeung, 2014). Hence, the SDQ I seems to constitute an appropriate instrument to study our research questions as it includes domainspecific scales (i.e., math, verbal) for the assessment of competence and affect selfperceptions, and has also been previously applied to study the interplay of competence and affect self-perceptions.

We chose students' effort at school as an outcome variable. Academic effort is an important educational outcome which influences student achievement (e.g., Marks, 2000) and has been investigated in other previous studies (e.g., Greene, DeBacker, Ravindran, \& Krows, 1999). In addition, by using effort as an outcome variable, we link our study to the findings from Pinxten et al. (2014) who demonstrated higher relations between affect self-perceptions and effort than between competence self-perceptions and effort. These results should be expanded to younger students in the present study.

\section{Method}

\section{Sample}

The sample of the present study consisted of 156 [89 (57.1\%) boys] German students attending the $3^{\text {rd }}$ grade of elementary school. The mean age of the students was 9.36 years $(S D$ $=0.44)$ as it is typical for $3^{\text {rd }}$ grade students in Germany. The students attended 28 different elementary schools all located in the same federal state in the southern part of Germany. Parental consent for participation was obtained for each participating student.

\section{Measures}

Competence and affect self-perceptions. Students' competence and affect selfperceptions related to school (i.e., academic self-concept in the SDQ terminology) was measured by the short German version of the SDQ I (SDQ I-GS; Arens, Yeung, Craven, \& 
Hasselhorn, 2013) that has been found to be a short, yet psychometrically sound measure for German preadolescents' multidimensional self-perceptions. In the present investigation, only the items relating to students' self-perceptions in the math and verbal (i.e., German language) domains were considered. The SDQ I-GS consists of three items asking for students' competence self-perceptions in math and German (i.e., I am good at math/German) and another three items relating to students' affect self-perceptions (i.e., affective-motivational responses) in math and German (i.e., I like math/German) (see Appendix). The items are formulated as single sentence statements. The students were asked to indicate on the 5-point Likert-type scale whether the statements were true, mostly true, sometimes false and sometimes true, mostly false or false. The coefficient alpha reliability estimates are good when assuming separate scales for the competence-related and affect-related items (German competence self-perceptions: $\alpha=.901$; German affect self-perceptions: $\alpha=.898$; math competence self-perceptions: $\alpha=.911$; math affect self-perceptions: $\alpha=.851$ ).

Effort. Students' effort at school was measured by a scale consisting of three items asking for students' willingness to invest effort in learning for school. On a 3-point Likerttype scale, the students had to indicate whether they agreed, disagreed, or neither agreed nor disagreed with the following questions: "Do you try to solve even very hard school tasks?; Do you try your best at school?; Do you look forward to unfamiliar tasks?" The coefficient alpha reliability estimate for the effort scale was $\alpha=.601$ in the present sample. Descriptive analyses revealed that the students used the full range of response options.

\section{Statistical Analyses}

We started the analyses with separate models for the math and verbal domains to verify the integrity of the measurement of the respective constructs as well as the separation between competence and affect self-perceptions on a domain-specific level. In this context, we stated 1-factor CFA models for students' self-perceptions in the math (Model 1 in Table 2) and verbal (Model 3) domains. In these models, one factor was assumed which encompassed 
both the respective competence-related and affect-related items. These models were then contrasted to 2-factor models (Model 2 for math, Model 4 for verbal) in which the two sets of items (competence-related and affect-related) defined separate constructs. We then proceeded to models in which self-perceptions for both math and verbal domains were considered. A 2factor model (Model 5) was compared to a 4-factor model (Model 6). The 2-factor model (Model 5) stated the domain specificity of academic self-perceptions without distinction between competence and affect facets as it assumed separate factors for math and verbal selfperceptions, which were defined by both the competence-related and affect-related items. By contrast, the 4-factor model (Model 6) assumed distinct factors for competence and affect self-perceptions in the math and verbal domains, which were modeled by the competencerelated and affect-related items of each domain. Hence, the 4-factor model (Model 6) comprised separate factors for math competence self-perceptions, math affect selfperceptions, verbal competence self-perceptions, and verbal affect self-perceptions.

We then expanded these models by including effort. Starting again with domainseparate analyses for the math and verbal domains, we included a factor for students' effort into Model 2 leading to Model 7. Model 7 thus stated separate factors for students' math competence self-perceptions, math affect self-perceptions, and effort. In order to examine whether the competence and affect factors were differentially related to effort, a latent regression model was conducted (Model 8) using competence and affect self-perceptions in math as independent variables and effort as the dependent variable. This sequence of analyses was then conducted for the verbal domain. In Model 11, we added a factor for effort to the separate factors for verbal competence and affect self-perceptions. Model 12 is the corresponding latent regression model to predict effort by verbal competence and affect selfperceptions. Afterwards, we considered the math and verbal domains simultaneously by stating a model with separate factors for math competence self-perceptions, math affect self- 
perceptions, verbal competence self-perceptions, verbal affect self-perceptions, and effort (Model 15) and the respective latent regression model (Model 16).

Some items used to measure competence and affect self-perceptions in math and verbal domains had the same item stems (e.g., "I am good at math / German"). To account for the shared method variance, correlated uniquenesses were integrated between parallel-worded items in all latent models (Marsh et al., 2013). All latent models reported in this study were run by the statistical package of Mplus, Version 7.0 (Muthén \& Muthén, 1998-2012). We chose the maximum likelihood estimator with robust standard errors (MLR) which has been found to be robust against any violations of normality assumptions. The full information maximum likelihood (FIML) method was used to estimate missing values (Enders, 2010). The amount of missing values was small in this sample $(0.79 \%)$. For evaluating the fit of the latent models, we present a wide range of common goodness-of-fit indices. We report the comparative fit index (CFI), the Tucker-Lewis index (TLI), the root mean square error of approximation (RMSEA), and the standardized root mean square residual (SRMR). For the CFI and TLI, values between .90 and .95 are indicative of a good model fit although Hu and Bentler (1999) recommend a stricter cut-off value of .95. Concerning the RMSEA, Browne and Cudeck (1993) propose that values near .05 indicate "close fit", values near .08 indicate "fair fit", and values above .10 indicate "poor fit". Regarding the SRMR, values between .08 and .10 are interpreted as a good model fit (e.g., Kline, 2005) although $\mathrm{Hu}$ and Bentler (1999) only consider values close to .08 as a good model fit. Given the controversially discussed cutoff values for the various goodness-of-fit indices, interpretation of model fit ultimately includes a degree of subjectivity in the researcher's judgment, and a wide range of fit indices should therefore be simultaneously considered (Marsh, Hau, \& Wen, 2004).

\section{Results}

Table 1 shows the descriptive statistics of the variables included in the study. The students were found to generally report high average levels of competence and affect self- 
perceptions related to the math and verbal domains. This finding of rather optimistic selfevaluations corresponds to those from other studies, particularly with elementary school children (Jacobs et al., 2002; Marsh \& Ayotte, 2003; Marsh \& Craven, 1997).

\section{Distinction between Competence and Affect Self-perceptions}

The 1-factor models combining the items for competence and affect self-perceptions into one factor resulted in unsatisfactory levels of fit for both the math (Model 1) and the verbal (Model 3) domains (Table 2). The 2-factor models separating between factors for competence self-perceptions and affect self-perceptions, however, presented perfect fit in both domains (Models 2 and 4). When considering the math and verbal domains simultaneously, the 4-factor model with the assumption of separate factors for competence and affect selfperceptions in math and verbal domains (Model 6) demonstrated a good model fit as indicated by all descriptive goodness-of-fit indices $(\mathrm{CFI}=.995, \mathrm{TLI}=.996, \mathrm{RMSEA}=.027, \mathrm{SRMR}=$ .044). This model demonstrated a better fit than the 2-factor model (Model 5), evident from the various descriptive goodness-of-fit indices as well as the significant result of the chisquare difference test for nested models estimated with the MLR estimator (Satorra, 2000): $\chi^{2} \operatorname{diff}(5)=130.60, p<.001$.

In this model (Model 6), the factors for competence and affect self-perceptions were well-defined in the math and verbal domains as the standardized loadings of the items on their corresponding factors were all of substantial size: math competence: .697 to $.880(M=.813)$; math affect: .804 to $.931(M=.882)$; German competence: .839 to $.873(M=.861)$; German affect: .839 to $.930(M=.871)$. Within the math and verbal domains, competence and affect self-perceptions were found to be highly but not perfectly correlated (math: $r=.762, p<.001$; German: $r=.767, p<.001)$ demonstrating the differentiation between competence and affect self-perceptions. Across the domains of math and German, competence and affect selfperceptions were unrelated to each other ( $r=-.040$ to .146$)$ demonstrating the domain specificity of academic self-perceptions. 


\section{Relations to Effort}

Starting with domain-specific models for examining the relations of competence and affect self-perceptions to effort, a factor for students' effort was added to separate factors for competence and affect self-perceptions in math (Model 7). This model showed a higher correlation between math affect self-perceptions and effort $(r=.413, p<.01)$ than between math competence self-perceptions and effort $(r=.315, p<.05)$. To further explore the differential relations of competence and affect self-perceptions to effort, Model 8 represents a latent regression model in which effort is predicted by competence and affect self-perceptions in math. This model is statistically equivalent to Model 7 and therefore resulted in the same fit. In this model, descriptively, only affect self-perceptions in math demonstrated a relation to effort $(\beta=.414)$ while competence self-perceptions were found to be unrelated to effort $(\beta=$ .001) although both coefficients were statistically non-significant. In a further step, we estimated models in which either the effect of affect self-perceptions on effort (Model 9) or the effect of competence self-perceptions (Model 10) were constrained to be zero. This approach that has also been realized in previous studies (e.g., Pinxten et al., 2014) allows for comparing the fit of these two models to gain further insight into presumptive differential relations of competence and affect self-perceptions to effort. In addition, in light of the small sample size of this study, models with fewer freely estimated model parameters result in more trustworthy results (Brown, 2009; Jackson, 2003). When constraining the effect of affect selfperceptions in math to zero (Model 9), students' competence self-perceptions in math demonstrated a substantial relation to students' effort $(\beta=.342, p<0.05)$. When constraining the effect of competence self-perceptions in math to zero (Model 10), however, affect selfperceptions in math demonstrated an even higher relation to students' effort $(\beta=.413, p<$ .01). Affect self-perceptions in math seem to be a better predictor for effort as Model 10 provided a better model fit $(\mathrm{CFI}=.960, \mathrm{TLI}=.942, \mathrm{RMSEA}=.072, \mathrm{SRMR}=.057)$ compared to Model $9(\mathrm{CFI}=.954, \mathrm{TLI}=.933, \mathrm{RMSEA}=.077, \mathrm{SRMR}=.069)$. In addition, 
the explained variance in students' effort was higher when predicted by math affect selfperceptions (Model 10: $R^{2}=.171$ ) than when predicted by competence self-perceptions (Model 9: $\left.R^{2}=.117\right)$.

The pattern of results was similar for the verbal domain. In Model 11 assuming separate factors for competence self-perceptions, affect self-perceptions, and effort, affect self-perceptions were found to be more highly correlated to effort $(r=.593, p<.001)$ than competence self-perceptions $(r=.402, p<.001)$. In the latent regression model (Model 12), only affect self-perceptions were found to be significantly related to effort $(\beta=.687, p<.01$ ), while competence self-perceptions demonstrated a non-significant relation $(\beta=-.123, n s)$. When constraining the effect of verbal affect self-perceptions on effort to zero (Model 13), the model fit was worse $(\mathrm{CFI}=.966, \mathrm{TLI}=.951, \mathrm{RMSEA}=.067, \mathrm{SRMR}=.067)$ and the explained variance in academic effort was lower $\left(R^{2}=.198\right)$ than when restricting the effect of verbal competence self-perceptions on effort to be zero $($ Model 14: CFI $=.987$, TLI $=.981$, $\left.\mathrm{RMSEA}=.041, \mathrm{SRMR}=.042 ; R^{2}=.345\right)$.

After the separate analyses for math and verbal domains, we conducted models which considered competence and affect self-perceptions in both math and verbal domains. Model 15 therefore integrated separate factors for math competence self-perceptions, math affect self-perceptions, German competence self-perceptions, German affect self-perceptions as well as for effort. The resulting correlations (Table 3) suggested higher correlations between affect self-perceptions in both math and verbal domains and effort (math: $r=.454, p<.001$; verbal: $r=.607, p<.001$ ) than between competence self-perceptions and effort (math: $r=.320, p<$ .05 ; verbal $r=.412, p<.001)$. Model 16 is a latent regression model in which effort is predicted by all four components of academic self-perceptions (i.e., math competence selfperceptions, math affect self-perceptions, German competence self-perceptions, German affect self-perceptions). In this model, affect self-perceptions in math $(\beta=.293)$ and verbal domains $(\beta=.583)$ were associated with effort but only the value for verbal affect self- 
perceptions was statistically significant $(p<.05)$. Competence self-perceptions related to both the math $(\beta=.097)$ and verbal $(\beta=-.024)$ domains were found to be unrelated to effort. When constraining the effects of affect self-perceptions in math and verbal domains to be zero (Model 17), students' competence self-perceptions for both the math $(\beta=.339, p<.05)$ and verbal $(\beta=.445, p<.001)$ domains demonstrated substantial relations to students' effort. However, when the effects of competence self-perceptions were fixed to zero (Model 18), affect self-perceptions related to math $(\beta=.379 p<.001)$ and verbal $(\beta=.550, p<.001)$ demonstrated higher relations to effort. As the fit was better for the latter model (Model 18: $\mathrm{CFI}=.976, \mathrm{TLI}=.968, \mathrm{RMSEA}=.047, \mathrm{SRMR}=.052)$ compared to Model $17(\mathrm{CFI}=.960$, $\mathrm{TLI}=.946, \mathrm{RMSEA}=.061, \mathrm{SRMR}=.068)$ and the explained variance in students' effort was higher $\left(R^{2}=.508, p<.001\right.$ vs. Model 17: $\left.R^{2}=.319, p<.05\right)$, affect self-perceptions in math and verbal domains seem to be more highly related to students' academic effort than competence self-perceptions.

\section{Discussion}

This study assessed competence and affect self-perceptions of $3^{\text {rd }}$ grade elementary school students in math and verbal domains along with self-reports of school effort. This design allowed for testing two yet underexplored research questions related to the separation between competence and affect self-perceptions in the context of the between-network approach, that is, when testing for their differential relations to outcome variables (Bryne, 1984). Previous studies offered respective evidence by demonstrating higher relations between competence self-perceptions and achievement (Arens et al., 2011; Meece et al., 1990; Pinxten et al., 2014; Wigfield, 1994). From the perspective of affect self-perceptions, affect self-perceptions were found to be more highly related to behavioral outcomes such as effort and coursework selection than competence self-perceptions (Marsh et al., 2013; Meece et al., 1990; Nagy et al., 2006; Pinxten et al., 2014). However, these studies have focused on secondary school students (Marsh et al., 2013; Meece et al., 1990; Nagy et al., 2006) or 
advanced elementary school students (Pinxten et al., 2014) and on the math/science domain. In our study, we therefore tested whether it is possible to generalize the existing betweennetwork evidence for the differentiability of affect self-perceptions from competence selfperceptions (due to higher relations to effort as a behavioral outcome variable) to $3^{\text {rd }}$ grade elementary school students and to the verbal domain.

The CFA results revealed a better model fit when assuming separate factors for competence and affect self-perceptions. This finding was similar when considering math and verbal domains separately and simultaneously. These results replicated corresponding findings from previous studies (Arens et al., 2011; Marsh \& Ayotte, 2003; Pinxten et al., 2014) and offered first support to the notion that even elementary school students in grade 3 distinguish between competence and affect self-perceptions in academic domains. This conclusion was further substantiated by latent regression models which demonstrated differential relations of competence and affect self-perceptions to effort. Irrespective of whether the math and verbal domains were considered separately or simultaneously, affect self-perceptions were found to be more strongly associated with school effort than competence self-perceptions. This finding matches previous research on older students which demonstrated higher relations between affect self-perceptions and behavioral outcomes such as effort or coursework selection (Marsh et al., 2013; Meece et al., 1990; Nagy et al., 2006; Pinxten et al., 2014), and extended them to younger elementary school students. Along with findings from previous studies (Arens et al., 2011; Marsh et al., 2013; Pinxten et al., 2014), the current state of research therefore indicates that for elementary and secondary school students alike, competence self-perceptions seem to be more highly related to achievement while affect self-perceptions seem to be more highly related to effort. Students' affective selfperceptions rather than students' competence self-perceptions might relate to their self-chosen extent of effort they invest into school work with higher levels of liking and enjoyment making students more inclined to expend higher levels of effort. Competence self-perceptions 
in turn might rather reflect students' objective achievement and are therefore less likely to be associated with students' self-paced academic behavior. While previous findings only related to the math/science domain (Marsh et al., 2013; Meece et al., 1990; Nagy et al., 2006; Pinxten et al., 2014), this study also offers support to the idea that compared to competence selfperceptions, affect self-perceptions and effort are also more highly related to each other in the verbal domain.

In the present study, students' effort was measured for school in general and not related to a specific academic domain, while academic self-perceptions were measured specifically related to math and verbal domains. Previous research has demonstrated the highest relations between self-perceptions and outcome measures when both measures pertain to the same content domain (Swann, Chang-Schneider, \& Larsen McClarty, 2007). The fact that we could demonstrate differential relations of competence and affect self-perceptions to effort even when the predictor (i.e., competence and affect self-perceptions) and outcome (i.e., effort) variables did not match in their domain specificity strengthens our conclusions regarding the separability and differential functionalities of competence and affect selfperceptions among elementary school students. However, given that previous research has implied the domain-specific nature of effort (e.g., Trautwein, Lüdtke, Roberts, Schnyder, \& Niggli, 2009), a more sophisticated approach would have considered the assessment of students' effort in math and verbal domains. Our conclusions therefore cannot be generalized to measures of domain-specific effort and other outcome variables. Besides, students' level of academic effort was assessed by self-ratings obtained from the students. Although this approach was also implemented in other studies (e.g., Chouinard, Karsenti, \& Roy, 2007; Pinxten et al., 2014), it would be interesting to choose more objective measures of academic behavior to study the relations to competence and affect self-perceptions, such as parent or teacher ratings of effort or perseverance. Although the SDQ I has been established as a reliable and valid instrument for the assessment of students' academic self-concepts and it has 
been already used for studying research questions outside the scope of self-concept research and theory (Trautwein et al., 2012), it should be kept in mind that this instrument has been originally designed within the framework of self-concept research and theory. Particularly the SDQ I scales for measuring affect self-perceptions need to be further scrutinized with respect to their underlying meaning. When looking at the items of the scales for measuring students' affect self-perceptions, it is obvious that they primarily address students' liking, enjoyment, and interest so that they may particularly depict constructs of intrinsic value (Nagy et al., 2006) or positive affect (Marsh et al., 2013; Marsh \& Yeung, 1996) rather than attainment value (personal importance), utility value (perceived usefulness), or cost as the other components of Wigfield and Eccles' (2000) conceptualization of the task value construct. Hence, the present findings should be tested for their generalization across different instruments which take other constructs for competence and affect self-perceptions into account. In this context, self-efficacy (Bandura, 1977) or outcome expectations (Wigfield \& Eccles, 2000) could serve as alternative conceptualizations of competence self-perceptions, while separate emotions (e.g., Pekrun, 2006) or other task value components derived from Wigfield and Eccles' (2000) classification could be used as alternative approaches to affect self-perceptions.

Although this study was focused on illustrating the separation between competence and affect self-perceptions, it is important to remember that both constructs overlap and are highly interrelated. Future research might therefore benefit from investigating the causal relationships among competence and affect self-perceptions and outcome criteria in longitudinal studies (see for example Marsh \& Craven, 2006; Jacobs et al., 2002). Such studies would also help to gain insight into the development of the separation between competence and affect self-perceptions and the strength of their outcome relations at various developmental stages. As the sample size of the present study was rather small and restricted to students from Germany, further studies should include a larger and more diverse sample for 
testing the generalizability of our findings. This would also allow methodological advantages such as taking into account students' clustering within classes or multi-group comparisons (e.g., boys and girls).

\section{References}

Abu-Hilal, M. M., Abdelfattah, F A., Alshumrani, S. A., Abduljabbar, A. S., \& Marsh, H. W. (2013). Construct validity of self-concept in TIMSS's student background questionnaire: a test of separation and conflation of cognitive and affective dimensions of self-concept among Saudi eighth graders. European Journal of Psychology of Education, 28, 1201-1220.

Arens, A. K., Yeung, A. S., Craven, R. G., \& Hasselhorn, M. (2011). The twofold multidimensionality of academic self-concept: Domain specificity and separation between competence and affect components. Journal of Educational Psychology, 103, 970-981.

Arens, A. K., Yeung, A. S., Craven, R. G., \& Hasselhorn, M. (2013). A short German version of the Self Description Questionnaire I: Theoretical and empirical comparability. International Journal of Research \& Method in Education, 36, 415-438.

Arens, A. K., Bodkin-Andrews, G., Craven, R. G., \& Yeung, A. S. (2014). Self-concept of Indigenous and non-Indigenous Australian students: Competence and affect components and relations to achievement. Learning and Individual Differences, 32, 93-103.

Bandura, A. (1977). Self-efficacy: Toward a unifying theory of behavioral change. Psychological Review, 84, 191-215.

Bong, M. (2001). Between- and within-domain relations of academic motivation among middle and high school students: Self-efficacy, task value, and achievement goals. Journal of Educational Psychology, 93, 23-34. 
Brown, T. A. (2006). Confirmatory factor analysis for applied research. New York: Guilford.

Browne, M. W., \& Cudeck, R. (1993). Alternative ways of assessing model fit. In K. A. Bollen, \& J. S. Long (Eds.), Testing structural equation models (pp. 136-162). Newbury Park, CA: Sage.

Brunner, M., Keller, U., Dierendonck, C., Reichert, M., Ugen, S., Fischbach, A. \& Martin, R. (2010). The structure of academic self-concepts revisited: The nested Marsh/Shavelson model. Journal of Educational Psychology, 102, 964-981.

Byrne, B. M. (1984). The general/academic self-concept nomological network: A review of construct validation research. Review of Educational Research, 54, 427-456.

Byrne, B. M. (1996). Measuring self-concept across the life span: Issues and instrumentation. Washington, DC: American Psychological Association.

Chouinard, R., Karsenti, T., \& Roy, N. (2007). Relations among competence beliefs, utility value, achievement goals, and effort in mathematics. British Journal of Educational Psychology, 77, 501-517.

Eccles, J. S. \& Wigfield, A. (1995). In the mind of the actor: The structure of adolescents' achievement task values and expectancy-related beliefs. Personality and Social Psychology Bulletin, 21, 215-225.

Eccles, J. S., Wigfield, A., Flanagan, C. A., Miller, C., Reuman, D. A., \& Yee, D. (1989). Self-concepts, domain values, and self-esteem: Relations and changes at early adolescence. Journal of Personality, 57, 283-310.

Eccles, J. S., Wigfield, A., Harold, R., \& Blumenfeld, P. B. (1993). Age and gender differences in children's self- and task perceptions during elementary school. Child Development, 64, 830-847.

Enders, C. K. (2010). Applied missing data analysis. New York: Guilford. 
Goetz, T., Frenzel, A. C., Hall, N. C., \& Pekrun, R. (2008). Antecedents of academic emotions: Testing the internal/external frame of reference model for academic enjoyment. Contemporary Educational Psychology, 33, 9-33.

Greene, B. A., DeBacker, T. K., Ravindran, B., \& Krows, J. A. (1999). Goals, values, and beliefs as predictors of achievement and effort in high school mathematics classes. Sex Roles, 40, 421-458.

Hu, L. T., \& Bentler, P. M. (1999). Cutoff criteria for fit indexes in covariance structure analysis: Conventional criteria versus new alternatives. Structural Equation Modeling, $6,1-55$.

Jackson, D. L. (2003). Revisiting sample size and number of parameter estimates: Some support for the N:q hypothesis. Structural Equation Modeling, 10, 128-141.

Jacobs, J. E., Lanza, S., Osgood, D. W., Eccles, J. S., \& Wigfield, A. (2002). Changes in children's self-competence and values: Gender and domain differences across grade one through twelve. Child Development, 73, 509-527.

Kline, R. B. (2005). Principles and practice of structural equation modeling. New York: Guildford.

Krapp, A. (1999). Interest, motivation and learning: An educational-psychological perspective. European Journal of Psychology of Education, 14, 23-40.

Leach, L.F., Henson, R.K., Odom, L.R., \& Cagle, L.S. (2006). A reliability generalization study of the Self-Description Questionnaire. Educational and Psychological Measurement, 66, 285-304.

Marks, H. (2000). Student engagement in instructional activity: Patterns in the elementary, middle, and high schools years. American Educational Research Journal,37, 153-184.

Marsh, H. W. (1990a). Self Description Questionnaire - I (SDQ I). Manual. Macarthur, N.S.W. Australia: University of Western Sydney. 
Marsh, H. W. (1990b). Self Description Questionnaire - II (SDQ II). Manual. Macarthur, NSW. Australia: University of Western Sydney.

Marsh, H. W. (1990c). The structure of academic self-concept: The Marsh/Shavelson model. Journal of Educational Psychology, 82, 623-636.

Marsh, H. W. (2007). Self-concept theory, measurement and research into practice: The role of self-concept in educational psychology. Leicester, UK: British Psychological Society.

Marsh, H. W., Abduljabbar, A. S., Abu-Hilal, M., Morin, A. J. S., Abdelfattah, F., Leung, K. C., Xu, M. K., Nagengast, B., \& Parker, P. (2013). Factor structure, discriminant and convergent validity of TIMSS math and science motivation measures: A comparison of USA and Saudi Arabia. Journal of Educational Psychology, 105, 108-128.

Marsh, H. W., \& Ayotte, V. (2003). Do multiple dimensions of self-concept become more differentiated with age? The differential distinctiveness hypothesis. Journal of Educational Psychology, 95, 687-706.

Marsh, H. W., \& Craven, R. G. (1997). Academic self-concept: Beyond the dustbowl. In G. Phye (Ed.), Handbook of classroom assessment: Learning, achievement and adjustment (pp. 131-198). Orlando, FL: Academic Press.

Marsh, H. W., \& Craven, R. G. (2006). Reciprocal effects of self-concept and performance from a multidimensional perspective. Beyond seductive pleasure and unidimensional perspectives. Perspectives on Psychological Science, 1, 133-163.

Marsh, H. W., Craven, R. G., \& Debus, R. (1999). Separation of competency and affect components of multiple dimensions of academic self-concept: A developmental perspective. Merrill-Palmer Quarterly, 45, 567-601.

Marsh, H. W., Hau, K.-T., \& Wen, Z. (2004). In search of golden rules: Comment on hypothesis-testing approaches to setting cutoff values for fit indexes and dangers in 
overgeneralizing Hu \& Bentler's (1999) findings. Structural Equation Modeling, 11, $320-341$.

Marsh, H. W., \& O’Neill, R. (1984). Self-Description Questionnaire III: The construct validity of multidimensional self-concept ratings by late adolescents. Journal of Educational Measurement, 21, 153-174.

Marsh, H. W., \& Yeung, A. S. (1996). The distinctiveness of affects in specific school subjects: An application of confirmatory factor analysis with the National Educational Longitudinal Study of 1988. American Educational Research Journal, 33, 665-689.

Marsh, H. W., \& Yeung, A. S. (1998). Longitudinal structural equation models of academic self-concept and achievement: Gender differences in the development of math and English constructs. American Educational Research Journal, 35, 705-738.

Meece, J. L., Wigfield, A., \& Eccles, J. S. (1990). Predictors of math anxiety and its influence on young adolescents' course enrollment intentions and performance in mathematics. Journal of Educational Psychology, 82, 60-70.

Möller, J., Pohlmann, B., Köller, O., \& Marsh, H. W. (2009). Meta-analytic path analysis of the internal/external frame of reference model of academic achievement and academic self-concept. Review of Educational Research, 79, 1129-1167.

Möller, J., Retelsdorf, J., Köller, O., \& Marsh, H. W. (2011). The reciprocal I/E model: An integration of models of relations between academic achievement and self-concept. American Educational Research Journal, 48, 1315-1346.

Muthén, L. K., \& Muthén, B. O. (1998-2012). Mplus user's guide ( $7^{\text {th }}$ ed.). Los Angeles, CA: Muthén \& Muthén.

Nagengast, B., Marsh, H.W., Scalas, L.F., Xu, M., Hau, K.-T, \& Trautwein, U. (2011). Who took the "x" out of expectancy-value theory? A psychological mystery, a substantivemethodological synergy, and a cross-national generalization. Psychological Science, 22, 1058-1066. 
Nagy, G., Trautwein, U., Köller, O., Baumert, J., \& Garrett, J. (2006). Gender and course selection in upper secondary education: Effects of academic self-concept and intrinsic value. Educational Research and Evaluation, 12, 323-345.

Pekrun, R. (2006). The control-value theory of achievement emotions: Assumptions, corollaries, and implications for educational research and practice. Educational Psychology Review, 18, 315-341.

Pinxten, M., Marsh, H. W., De Fraine, B., Van Den Noortgate, W., \& Van Damme, J. (2014). Enjoying mathematics or feeling competent in mathematics? Reciprocal effects on mathematics achievement and perceived math effort expenditure. British Journal of Educational Psychology, 84, 152-174.

Satorra, A. (2000). Scaled and adjusted restricted tests in multi-sample analysis of moment structures. In R .D. H Heijmans, D. S. G. Pollock \& A. Satorra (Eds.), Innovations in multivariate statistical analysis. A Festschrift for Heinz Neudecker (pp. 233-247). London: Kluwer Academic Publishers.

Schunk, D. H., Pintrich, P. R., \& Meece, J. L. (2009). Motivation in education: Theory, research, and applications ( $3^{\text {rd }}$ edition). Upper Saddle River, NJ: Pearson.

Swann, W. B., Jr., Chang-Schneider, C., \& Larsen McClarty, K. (2007). Do people's selfviews matter? Self-concept and self-esteem in everyday life. American Psychologist, $62,84-94$.

Trautwein, U., Lüdtke, O., Roberts, B. W., Schnyder, I., \& Niggli, A. (2009). Different forces, same consequence: Conscientiousness and competence beliefs are independent predictors of academic effort and achievement. Journal of Personality and Social Psychology, 97, 1115-1128.

Trautwein, U., Marsh, H.W., Nagengast, B., Lüdtke, O., Nagy, G., \& Jonkmann, K. (2012). Probing for the multiplicative term in modern expectancy-value theory: A latent interaction modeling study. Journal of Educational Psychology, 104, 763-777. 
Wigfield, A. (1994). Expectancy-value theory of achievement motivation: A developmental perspective. Educational Psychology Review, 6, 49-78.

Wigfield, A., \& Eccles, J. S. (1994). Children's competence beliefs, achievement values, and general self-esteem: Change across elementary and middle school. The Journal of Early Adolescence, 14, 107-138.

Wigfield, A., Eccles, J. S., Yoon, K. S., Harold, R. D., Arbreton, A. J. A. Freedman-Doan, C., \& Blumenfeld, P. C. (1997). Change in children's competence beliefs and subjective task values across elementary school years: A 3-year study. Journal of Educational Psychology, 89, 451-469.

Wigfield, A., \& Eccles, J. S. (2000). Expectancy-value theory of achievement motivation. Contemporary Educational Psychology, 25, 68-81.

Valentine, J. C., DuBois, D. L., \& Cooper, H. (2004). The relation between self-beliefs and academic achievement: A meta-analytic review. Educational Psychologist, 39, 111131. 
Table 1

Descriptive Statistics

\begin{tabular}{lccc} 
& $M$ & $S D$ & $M$ range \\
\hline competence self-perceptions in math & 4.21 & 0.88 & $1.33-5.00$ \\
affect self-perceptions in math & 3.89 & 1.18 & $1.00-5.00$ \\
competence self-perceptions in verbal & 3.90 & 1.04 & $1.00-5.00$ \\
affect self-perceptions in verbal & 3.55 & 1.22 & $1.00-5.00$ \\
effort & 2.63 & 0.41 & $1.00-3.00$
\end{tabular}


Table 2

Goodness-of-Fit Indices of Alternative CFA Models

\begin{tabular}{|c|c|c|c|c|c|c|c|}
\hline Model & $\chi^{2}$ & df & CFI & TLI & RMSEA & SRMR & Model description \\
\hline 1 & 63.761 & 9 & .850 & .750 & .197 & .074 & 1-factor model for math \\
\hline 2 & 8.168 & 8 & 1.000 & .999 & .012 & .019 & 2-factor model for math (separation between competence and affect self-perceptions) \\
\hline 3 & 75.794 & 9 & .820 & .701 & .218 & .062 & 1-factor model for verbal \\
\hline 4 & 4.653 & 8 & 1.000 & 1.017 & .000 & .017 & 2-factor model for verbal (separation between competence and affect self-perceptions) \\
\hline 5 & 204.755 & 48 & .839 & .779 & .145 & .079 & 2-factor model (domain specificity of academic self-perceptions) \\
\hline 6 & 48.048 & 43 & .995 & .992 & .027 & .044 & $\begin{array}{l}\text { 4-factor model (domain specificity and separation between competence and affect self- } \\
\text { perceptions) }\end{array}$ \\
\hline 7 & 46.555 & 24 & .955 & .933 & .078 & .057 & 2 -factor model for math and 1 factor for effort \\
\hline 8 & 46.555 & 24 & .955 & .933 & .078 & .057 & Latent regression model for math \\
\hline 9 & 48.354 & 25 & .954 & .933 & .077 & .069 & $\begin{array}{l}\text { Latent regression model for math with effects of affect self-perceptions on effort } \\
\text { constrained to zero }\end{array}$ \\
\hline 10 & 45.419 & 25 & .960 & .942 & .072 & .057 & $\begin{array}{l}\text { Latent regression model for math with effects of competence self-perceptions on effort } \\
\text { constrained to zero }\end{array}$ \\
\hline 11 & 31.655 & 24 & .985 & .978 & .045 & .042 & 2-factor model for verbal and 1 factor for effort \\
\hline 12 & 31.655 & 24 & .985 & .978 & .045 & .042 & Latent regression model for verbal \\
\hline 13 & 42.471 & 25 & .966 & .951 & .067 & .067 & $\begin{array}{l}\text { Latent regression model for verbal with effects of affect self-perceptions on effort } \\
\text { constrained to zero }\end{array}$ \\
\hline 14 & 31.687 & 25 & .987 & .981 & .041 & .042 & $\begin{array}{l}\text { Latent regression model for verbal with effects of competence self-perceptions on effort } \\
\text { constrained to zero }\end{array}$ \\
\hline 15 & 104.164 & 75 & .974 & .964 & .050 & .052 & $\begin{array}{l}\text { 4-factor model (domain specificity and separation between competence and affect self- } \\
\text { perceptions) and } 1 \text { factor for effort }\end{array}$ \\
\hline 16 & 104.164 & 75 & .974 & .964 & .050 & .052 & Latent regression model for math and verbal \\
\hline 17 & 121.819 & 77 & .960 & .946 & .061 & .068 & $\begin{array}{l}\text { Latent regression model for math and verbal with effects of affect self-perceptions on } \\
\text { effort constrained to zero }\end{array}$ \\
\hline 18 & 103.469 & 77 & .976 & .968 & .047 & .052 & $\begin{array}{l}\text { Latent regression model for math and verbal with effects of competence self- } \\
\text { perceptions on effort constrained to zero }\end{array}$ \\
\hline
\end{tabular}

Note. All models were estimated by the maximum likelihood estimator with robust standard errors (MLR) and integrated correlated uniquenesses between parallel-worded items.

CFI = Comparative Fit Index, TLI = Tucker-Lewis-Index, RMSEA = Root Mean Square Error of Approximation, CI = confidence interval, SRMR

$=$ Standardized Root Mean Squared Residual. 
Table 3

Standardized Factor Correlations of Model 15 in Table 2

\begin{tabular}{|c|c|c|c|c|}
\hline & Math competence & Math affect & German competence & German affect \\
\hline Math affect & $.763 * *$ & & & \\
\hline German competence & .022 & -.040 & & \\
\hline German affect & .000 & .148 & $.766 * *$ & \\
\hline Academic effort & $.320 *$ & $.454 * *$ & $.412 * *$ & $.607 * *$ \\
\hline
\end{tabular}




\section{Appendix}

Items Used for Measuring Students' Competence and Affect Self-Perceptions in Math and Verbal Domains

\section{Math Competence Self-Perceptions}

1. Work in mathematics is easy for me.

2. I learn things quickly in mathematics.

3. I am good at mathematics.

\section{Math Affect Self-Perceptions}

1. I like mathematics.

2. I am interested in mathematics.

3. I look forward to mathematics.

\section{Verbal Competence Self-Perceptions}

1. I am good at German.

2. Work in German is easy for me.

3. I learn things quickly in German.

\section{Verbal Affect Self-Perceptions}

1. I like German.

2. I enjoy doing work in German.

3. I look forward to German. 